\title{
Mecanismos de distanciamento linguístico: a preservação da face na síntese documental
}

Rosane Suely Alvares Lunardelli

\author{
Bibliotecária, mestre e doutora em Estudos da \\ Linguagem, professora associada do \\ Departamento de Ciência da Informação na \\ Universidade Estadual de Londrina
}

http://dx.doi.org/10.1590/1981-5344/2761

Caracterizado como metarrepresentação das ideias vinculadas em outro texto, o resumo científico constituise em relevante instrumento de recuperação da informação, do conhecimento. Elaborado pelo autor do texto que o originou ou por profissionais especializados, sua construção baseia-se em normas específicas. Dentre os vários requisitos apresentados para sua elaboração, tem-se como objetivo investigar aquele que busca a elaboração de um microtexto que privilegie um estilo objetivo, neutro, isento. Um dos procedimentos voltados à consecução dessa proposta, de acordo com esses materiais normativos, é o emprego da terceira pessoa do singular o que possibilitaria o distanciamento do produtor com seu enunciado. Por meio de estudo teórico-reflexivo, entretanto, verificou-se que, embora as normas e grande parte da comunidade científica defendam essas premissas, a impessoalidade não promove 0 distanciamento do locutor com seu enunciado uma vez que há intencionalidade, ainda que subjacente, na produção textual. O autor jamais se afasta totalmente de seu texto, pois não existe texto sem enunciador. Diante do exposto, o que efetivamente se consegue, por meio dessas estratégias linguísticas, são efeitos de sentido, empregados pelo autor tendo em vista a autoimagem que deseja projetar.

Palavras-chave: Resumo científico; Preservação da face; Impessoalidade discursiva; Ciência da Informação. 


\section{Linguistic distancing mechanisms: face preservation in documentary synthesis}

Characterized as the metarepresentation of the linked ideas in another text, the scientific summary is a relevant retrieval instrument of knowledge. Prepared by its original author or specialized professionals, its construction is based on specific rules. Among the various requirements set for its elaboration, we have to investigate the development of a microtext that favors an objective, impartial and neutral style. One of the procedures aimed at achieving such proposal, according to the normative materials, is the use of the third person singular, which would allow the author to distance oneself from the production. Through the theoretical-reflective study, it has been found that, although the rules and much of the scientific community defend such assumptions, impersonality does not promote the speaker's distance from one's statement since there is intentionality, even though it may be underlying the text. The author never departs completely from their text, once there is not a text without enunciation. Given the above, what is actually achieved through these linguistic strategies are effects on meaning, used by the author in view of the self-image they wish to project.

Keywords: Scientific summary; Preservation of the face; Discursive impersonality; Information Science.

Recebido 16.04.2016 Aceito em 13.02.2017

\section{Introdução}

Em tempos atuais, a capacidade de síntese, em especial a produção de textos concisos e objetivos, traduz-se em habilidade significativamente valorizada. No contexto dos discursos científicos, o resumo desempenha um importante papel no que diz respeito à organização e recuperação da informação, do conhecimento registrado.

Considerado como a representação da representação, ou seja, metarrepresentação da informação registrada institui-se como o recurso de descrição do conteúdo temático de objetos informacionais que mais se aproxima do texto original.

Questões relacionadas aos resumos, de acordo com Guimarães (2005, p. 3, grifo do autor), "integra, no âmbito da Ciência da Informação, o denominado tratamento de conteúdo documental [...]". Caracterizado 
como processo cognitivo de alta complexidade, esse tipo de tratamento documental busca representar o conteúdo dos mais diversos recursos informacionais por intermédio de sua condensação (resumo) ou de sua indexação. Lancaster (2004, p. 6) evidencia a estreita relação entre as atividades de elaboração do resumo e indexação ao esclarecer que "ambas implicam a preparação de uma representação do conteúdo temático". Dando continuidade ao raciocínio, o autor ressalta que ambas as ações têm o mesmo propósito que é o de apresentar o conteúdo de forma sintética e assim possibilitar ao leitor a decisão pelo acesso ou não à informação, ao documento.

De acordo com Moreiro González (2004, tradução nossa), o resumo retextualiza uma mensagem com a mesma organização do documento estruturado. É um texto que reproduz o outro texto, com nível de relevância similar. Comunga-se no estudo em tela, com a concepção de Costa Val (1999, p. 3) a qual considera o texto como "ocorrência linguística falada ou escrita, de qualquer extensão, dotada de unidade sociocomunicativa, semântica e formal".

Produto da síntese realizada, sua elaboração é resultado de processo cognitivo de relativa complexidade, o qual consiste em identificar a informação mais relevante e reapresentá-la o mais fidedignamente possível. Trata-se de uma reunião das ideias, premissas e fatos principais apresentados no texto original. Deve-se respeitar a ordem, a estrutura, o sentido estabelecido pelo autor e redigi-lo de forma condensada.

Na perspectiva de Lancaster (2004), os resumos facilitam a escolha, pois auxiliam o leitor a resolver se determinado item atende ou não à sua necessidade informacional. O autor mencionado salienta que o resumo deve servir para atingir alguns objetivos, tais como: transmitir a informação; evidenciar o que é mais importante no documento original; facilitar a compreensão do texto original uma vez que antecede o texto; "[...] esclarecer o conteúdo de documentos escritos em línguas que 0 leitor desconheça" (LANCASTER, 2004, p. 103-104).

Elaborado pelo autor do texto (são consideradas como expressões sinônimas: autor/locutor/enunciador) ou por profissionais especializados, sua construção baseia-se nas prescrições oriundas da Norma 6028 da Associação Brasileira de Normas Técnicas (ABNT, 2003), de livros de metodologia da pesquisa científica e outras fontes.

Dentre essas indicações, é foco do estudo aquela que busca a elaboração de um microtexto que privilegie um estilo objetivo, neutro, isento. Um dos procedimentos voltados à consecução desse objetivo, de acordo com esses materiais, é o emprego da terceira pessoa do singular. Os autores, nessa perspectiva, "apresentam-se, procurando esconder-se enquanto sujeitos agentes do processo discursivo, mascarando sua presença num estilo universalmente aceito por seus pares" (TASCHETTO, 2011, p. 30).

De acordo com essa linha de raciocínio, a impessoalidade, o distanciamento do autor em relação ao texto, conseguido por intermédio dessa forma linguística, é desejável, uma vez que essa estratégia discursiva projeta uma imagem de competência, profissionalismo, além de 
impedir que seja considerado arrogante, desprovido de humildade científica. Entretanto, ainda que essa proposta permeie alguns estudos, importa lembrar que o discurso científico, mesmo "reivindicando a objetividade, a neutralidade e a monotonia, pode ser avaliado como usando recursos de qualquer outra retórica". (TASCHETTO, 2011, p. 28).

Diante dessas questões aparentemente contraditórias, buscou-se, por intermédio de estudo teórico, refletir a respeito da valorização da proposta de impessoalidade, de distanciamento dos sujeitos agentes no processo de elaboração de resumos documentários, ou seja, aqueles produzidos no meio acadêmico ou científico. Como fundamentação teórica, recorreu-se aos aportes teóricos e metodológicos da Organização, subárea da Ciência da Informação, na Linguística Textual, na Análise da Conversação e da Preservação da Face e seus estudos sociointeracionistas.

\section{Resumo}

De acordo com Kobashi (1997), o ato de resumir pressupõe a seleção de informações consideradas relevantes com o intuito de produzir - para um tipo de leitor previamente identificado - outro texto com expressivo grau de similaridade com o texto que o originou. Prosseguindo, a autora argumenta que "trata-se de um ato cognitivo com finalidades comunicativas que supõe: a) compreender e selecionar conteúdos informacionais de natureza textual; b) escolher formas de expressão específicas para representa-los" (KOBASHI, 1997, p. 201). Nesse sentido, vale mencionar que todo processo de produção textual tem uma dimensão cognitiva, pois envolve o emprego consciente de estratégias linguísticas e discursivas.

Seguindo a Associação Brasileira de Normas Técnicas (ABNT/NBR $6028^{1}$ apud SEVERINO, 2002), observa-se que a elaboração de resumos de qualidade está estreitamente relacionada aos seguintes aspectos: concisão (máximo de informação em um mínimo de extensão); objetividade (máximo de compreensão/mínimo de tempo de leitura) e precisão (emprego de termos específicos da área).

Luz considera a concisão, a precisão, a clareza e a integridade ou completude como qualidades essenciais de um resumo. A concisão, de acordo com a autora, se dá por intermédio do emprego de técnicas linguísticas. Nesse sentido, "Devem ser eliminadas redundâncias (comuns em todas as línguas naturais), repetições enfáticas, recomendações, recursos persuasivos e floreios estilísticos". (LUZ, 1996, p. 2). A precisão é alcançada por meio da utilização de palavras que expressem de forma fidedigna os conceitos, as ideias apresentadas no texto fonte. Relacionada à compreensão, a clareza "requer um estilo fácil e transparente, que possibilite ao leitor concentrar-se nas eventuais dificuldades de conteúdo". (LUZ, 1996, p. 28). A integridade, segundo a autora, é a característica de

\footnotetext{
${ }^{1}$ ASSOCIAÇÃO BRASILEIRA DE NORMAS TÉCNICAS (ABNT). NBR 6028: informação e documentação - resumo - apresentação. Rio de Janeiro, 2003.
} 
um texto que não necessita da leitura do original para que seja compreendido. "A despeito da necessidade de brevidade, os resumos devem ser auto-suficientes; não se logrará um dos principais objetivos do resumo se o leitor tiver que consultar o original para entender o resumo!" (LANCASTER, 2004, p. 114).

Moreiro González (2004, tradução nossa) apresenta cinco fatores que devem ser considerados no momento de sua composição.

O primeiro diz respeito à entropia, que é a capacidade de expressar o conteúdo do texto original utilizando o menor número de palavras, com o intuito, como apresenta Guimarães (2005, p. 9), de "[...] assegurar a função comunicativa do resumo, adequando-se ao contexto do documento e ao de uma comunidade usuária (ainda que potencial)." O segundo, a pertinência, ou seja, a qualidade de adaptar o resumo a fatores como fidelidade ao texto que resume e ao nível de conhecimento e necessidades informacionais dos possíveis leitores. A coerência está relacionada ao encadeamento lógico dos tópicos. O quarto fator, a correção linguística, é responsável pelo atendimento às normas da linguagem adequada a esse tipo de texto. Finalmente, a informatividade, ou seja, a priorização da informação principal em detrimento daquelas consideradas acessórias.

Quanto à finalidade e nível de especificidade dos resumos, a NBR 6028 (ABNT, 2003) os caracteriza como indicativo, informativo e crítico. 0 resumo indicativo tem como propósito descrever pontos principais do documento, sem a inserção de dados quantitativos e qualitativos. Normalmente, requer a consulta ao texto que o originou. Já o informativo, como o próprio nome elucida, apresenta informações relacionadas à finalidade do documento, os resultados e conclusões apresentadas, dispensando a consulta ao texto fonte. O resumo crítico, a resenha, é elaborado por especialistas e, além da condensação do documento original, apresenta juízo de valor, análise crítica.

No que tange à sua extensão, a ABNT/NBR 6028 estabelece de 150 a 500 palavras para trabalhos acadêmicos, científicos (relatórios técnicocientíficos, teses, dissertações e outros). Os artigos de periódicos devem ter de 100 a 250 palavras; notas e textos breves, de 50 a 100 palavras (ABNT, 2003).

Quanto ao conteúdo informacional, deve apresentar o objetivo, procedimentos metodológicos, resultados e comentários finais ou conclusão. De acordo com a Norma mencionada (ABNT, 2003, p. 2), "A ordem e extensão destes itens dependem do tipo de resumo (informativo ou indicativo) e do tratamento que cada item recebe no documento original".

Respaldado por critérios de objetividade, o resumo deve ter parágrafo único com encadeamento de "frases concisas, afirmativas e não de enumeração de tópicos" (ABNT, 2003, p. 2).

A primeira frase, segundo a Norma supracitada, deve ser representativa do conteúdo temático, seguida de frases que evidenciem características ou a tipologia do trabalho fonte, por exemplo, estudo de caso, história oral e outras. 
A utilização, pelo resumidor, da mesma lexia empregada no texto fonte é uma questão controversa. Na perspectiva de alguns estudiosos, é recomendável o uso do mesmo vocabulário do autor do texto original uma vez que tal procedimento dificultaria distorções; para outros, o que deve prevalecer no microtexto são as ideias do texto fonte e não suas palavras ou frases.

No que diz respeito ao conteúdo do resumo científico, são várias as propostas de sua estrutura informacional. De modo geral, elas indicam que os objetivos, a metodologia, resultados e conclusões são itens fundamentais à sua qualidade. Podem também serem apresentadas, de forma sucinta, algumas "informações suplementares como modificações de métodos, novos compostos ou novas fontes de dados [...], sem que, para isso, o texto do resumo se distancie do tema principal". (LUZ, 1996, p. 31).

Em concordância com diversos estudiosos da temática, entre os quais, Luz (1996), Kobashi (1997), Guimarães (2005), considera-se como impróprios à sua elaboração o uso excessivo de palavras e explicações; frases longas; repetições de premissas e/ou resultados apresentados no texto original; a inadequação do vocabulário ao público a que se destina; palavras de cunho polissêmico; adjetivos, uma vez que pressupõem juízo de valor; apostos, por truncarem a oração; flexões dos verbos em sua fora original ; termos verbais menos comuns; construções frasais mais complexas; figuras de linguagem; termos estrangeiros e siglas pouco conhecidas; utilização de frases referenciais, como por exemplo, o presente artigo...; repetição do título do texto ou de exemplos do texto fonte; variação de sinônimos para representar a mesma ideia.

Com o intuito de contribuir com a elaboração de um texto direto, conciso e de expressiva força argumentativa, a norma (ABNT, 2003, p. 2) indica o emprego do verbo na voz ativa e na terceira pessoa do singular.

Müller e Cornelsen (2003, p. 92) defendem a ideia de que, além da precisão, clareza, coerência, a imparcialidade e a impersonalidade, são qualidades exigidas na linguagem científica, "Assim, recomenda-se o uso de verbo na terceira pessoa, evitando-se pronomes da primeira pessoa tanto no plural como no singular [...]". Tal proposta encontra justificativa na proposição de que, no texto científico, não cabe a presença do autor, dado que apenas o estudo realizado, o assunto explorado, tem relevância ou validade. Sendo assim, o modo impessoal promoveria o distanciamento, como se os fatos narrados não afetassem diretamente aquele que elaborou o trabalho.

Ao referir-se à dicotomia objetividade/subjetividade ou presença/ ausência na produção de textos de caráter acadêmico-científico, Coracini (1991, p. 111) alerta para o fato de que o conceito de objetividade é dependente da interpretação particular:

[...] para uns, não se rompe a objetividade usando a primeira pessoa (antes, ela é garantida pela função dêitica), para outros, a única estratégica aceitável em termos de tempo e pessoa, é o uso de formas passivas e de sujeito indeterminado ou na $3^{a}$ pessoa. 
Segundo Rodrigues (1994, p. 17), "A concepção habitualmente divulgada a respeito do fazer do narrador, do teórico e do tradutor é a de que todos os três são considerados neutros e objetivos, escrevem sobre fatos, dados acontecimentos, traduzem o mundo, a realidade, os textos". Entretanto, essa ideia vem de encontro àquela defendida pela abordagem interacionista, de que o autor, o pesquisador é dotado de intencionalidade, cujas tomadas de decisões, comuns a todas as pesquisas, como a escolha do que pesquisar, qual enfoque abordar, quais preceitos metodológicos seguir, são movimentos que o instituem como um ser enunciador, responsável pelo estudo que realiza. Em decorrência, a pretensa neutralidade de muitos discursos é, de acordo com Koch (1992, p. 60), "apenas uma máscara, uma forma de representação [...]" e justifica a afirmação ao argumentar que

[...] o locutor se representa no texto 'como se' fosse neutro, 'como

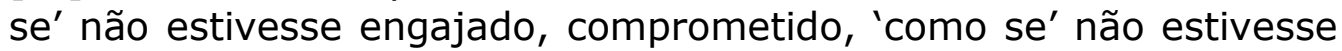
tentando orientar o outro para determinadas conclusões no sentido de obter dele determinados comportamentos e reações.

Ainda que não seja consensual entre produtores de textos científicos - e aqui especificamente, o resumo -, observa-se, como marca recorrente desse gênero textual, o emprego de formas impessoais. O autor do microtexto, nesse cenário, apresenta-se escondendo-se, procurando criar a ilusão de apagamento, de distanciamento. Para tanto, recorre ao emprego da partícula "se" (objetivou-se,) como indeterminador do sujeito; da adjetivação; da modalização do enunciador (é possível, é provável que), utilizando formas de expressão como "É necessário que..." entre outras.

De acordo com esse contexto, "O sujeito-enunciador assume a postura de um observador distante do objeto observado, como que provando, com sua ausência explícita, a ausência do sujeito-pesquisador na etapa científica" (CORACINI, 1991, p. 104). Contudo, a autora ressalta que, ao mesmo tempo em que se afastam do texto, "as instâncias enunciativas se revelam sub-repticiamente através dos mesmos recursos linguísticos".

Sob a ótica discursiva, considera-se que, ainda que o escritor do resumo científico e o leitor não estejam frente a frente, isso não significa que não exista interação, pois, ao escrever, o produtor do texto leva em conta o leitor, suas características e necessidades informacionais. Buscando criar e manter a interação, o autor do texto "apresenta um conjunto de argumentos com uma certa ordem e finalidade, visando também a uma relação intersubjetiva, isto é, pretende levar o outro a acreditar no que diz, a desejar alguma coisa ou a agir de uma certa maneira" (ANDRADE, 1995, p. 56). Dando continuidade, a autora evidencia o movimento dialógico instituído ao mencionar que, de um lado, tem-se o autor e sua intenção de conseguir a adesão do leitor. "É ele quem sustenta uma tese ou teoria e busca influenciar ou mesmo transformar o comportamento de seu interlocutor ou ainda pretende fazer com que este compartilhe de suas opiniões" (ANDRADE, 1995, p. 55). Do outro lado, tem-se o interlocutor ou leitor, aquele que acata ou refuta a proposição, a argumentação apresentada. A argumentatividade, cabe lembrar, 
manifesta-se - ainda que em diferentes graus - em outros gêneros textuais, além daqueles considerados tradicionalmente argumentativos.

Acompanhando pressupostos canonizados da semiótica discursiva, Barros (2005, p. 226) esclarece que "toda comunicação é um forma de manipulação: o destinador propõe ao destinatário um contrato, um acordo, com o objetivo de levá-lo a acreditar em certos valores [...]." Esse fazer persuasivo, de acordo com a autora, tem como finalidade convencer o destinatário da verdade do seu enunciado e da sua importância para ele e para a área em questão.

Para alcançar seu intento, o autor utiliza uma série de estratégias discursivas ou interacionais, como aquelas que buscam proteger a sua imagem e a do seu interlocutor em evento comunicativo, por exemplo, o resumo.

\section{A preservação da face na construção do resumo científico}

Qualquer discurso (texto) oral ou escrito, como anteriormente mencionado, é resultado da interação entre escritor/locutor e o leitor/ouvinte. Entretanto, para que isso aconteça de forma satisfatória, é necessário que se estabeleça uma situação de equilíbrio, de cooperação, de respeito, entre os participantes. Nesse sentido, como assevera Rosa (1992, p. 9), "[...] todo discurso manifesta o esforço de cada enunciador fazer crer naquilo que diz, isto é, o objetivo último de todo discurso é o de parecer e ser verdadeiro para o enunciatário, de modo que este possa crer no conteúdo que é enunciado".

$\mathrm{Na}$ elaboração do texto científico ou de sua representação, o autor sabe que corre riscos como ser corrigido, desacreditado ou até ser considerado arrogante, desprovido de modéstia, por exemplo, e, portanto, suscetível a danos em sua reputação como pesquisador.

Com o propósito de se resguardar de possíveis opiniões indesejadas, adota procedimentos de caráter linguístico que auxiliam na construção e manutenção de imagem positivamente ratificada pela sociedade. Considerados como mecanismos de preservação da face (autoimagem), esses recursos buscam evidenciar a imagem de si que o escritor quer projetar.

A preservação da face, na perspectiva de Goffman (1980), está diretamente relacionada ao valor social que um indivíduo reclama para si. Nesse sentido, o autor esclarece que "caso se queira lidar consigo mesmo e com os outros deve-se ter um repertório de práticas salvadoras de face para cada uma dessas possíveis relações com a ameaça”. (GOFFMAN, 1980, p. 84). Algumas dessas práticas podem ser consideradas defensivas e outras protetoras ou ambas as funções ao mesmo tempo.

Contribuindo para o desenvolvimento da temática, Brown e Levinson (1987) subdividiram a face em positiva e negativa e ressaltam que o indivíduo possui as duas faces, as quais, de forma consciente ou não, busca apresentar ou esconder. A face positiva diz respeito à imagem favorável que deseja que os outros tenham de si, e a negativa seria aquela que o interlocutor busca esconder.

Os procedimentos, as ações linguísticas empregadas para elaborar, manter ou restabelecer a face positiva do autor são denominados processos de figuração ou de negociação de imagem. Segundo Goffman (1980), existem duas categorias de figuração: os procedimentos de evitação, quando não são abordados assuntos, questões, enfoques ou até mesmo palavras que possam suscitar reações indesejadas e, com isso, prejudicar a manutenção da autoimagem, e os 
procedimentos de reparação, que são empregados quando há necessidade de restabelecer ou restaurar o equilíbrio interacional rompido anteriormente.

Dentre os mecanismos que evitam as possíveis ameaças à elaboração da face, propõe-se, no estudo em pauta, evidenciar recursos discursivos atenuadores que buscam promover o distanciamento do autor com o texto que produziu.

A atenuação, como argumenta Briz (2013, p. 285), "é uma categoria pragmática, um mecanismo estratégico e tático (portanto, intencional), que se relaciona à efetividade e à eficácia do discurso, ao alcance dos objetivos na interação [...]." Continuando a explanação, o autor evidencia a dualidade existente no processo de atenuação ao mencionar que "a atenuação é um mecanismo estratégico de distanciamento linguístico da mensagem e, por sua vez, de aproximação social." (BRIZ, 2013, p. 286). Atenuação, de acordo com Briz (2013), no âmbito discursivo, significa distância; no contexto social, representa aproximação, aceitação.

O emprego de estratégias atenuadoras que indicam maior ou menor envolvimento nos resumos é de extrema relevância, uma vez que, como argumenta Galembeck (1999, p. 175), "[...] os interlocutores sabem que a manifestação direta de opiniões pode torná-los vulneráveis a críticas e opiniões contrárias".

\subsection{Mecanismos de atenuação}

Considerados como efeito de sentido que se deseja suscitar, os mecanismos de atenuação funcionam como uma espécie de anteparo, de proteção à imagem do pesquisador, produtor de textos de caráter científico. São recursos linguísticos que procuram, antecipadamente, reduzir o comprometimento resultante da enunciação e, com isso, evitar seu caráter impositivo. De uma perspectiva mais pormenorizada, Rosa (1992, p. 29) divide esses elementos discursivos mitigadores em marcadores e procedimentos de atenuação. Entretanto, cabe mencionar que, no presente estudo, não é feita distinção entre esses recursos e todas as estratégias de abrandamento são consideradas como procedimentos de atenuação.

Vários autores, entre eles Rosa (1992), Marcuschi (1998), Galembeck (1999), Lunardelli (2007), apresentam como procedimentos de atenuação os seguintes recursos: o emprego da forma passiva, a indeterminação do sujeito, impessoalização (oração sem sujeito), verbos e advérbios parentéticos, hedges (evasivas), marcadores de distanciamento, entre outros. A inserção de trechos ou de ideias de autores positivamente reconhecidos (citações), o eufemismo e a relativização das asserções também contribuem para 0 abrandamento da discordância e, consequentemente, do "ataque" às faces presentes na interação.

A opção pelo uso de determinado procedimento, importa ressaltar, está relacionado ao gênero textual produzido e ao grau de formalidade que o institui. Quanto maior for o grau de formalidade estabelecido no texto, maior será a necessidade de atenuação, de cuidados para "poupar" as faces dos interlocutores. Em textos científicos, é fato, impera a necessidade e a relevância de preservar a face por intermédio de procedimentos ou estratégias como aquelas que promovam a ideia de distanciamento ou o apagamento até das marcas de autoria. Alguns desses recursos discursivos são apresentados a seguir.

Quadro 1 - Procedimentos discursivos de atenuação linguística 


\begin{tabular}{c|c|l|l}
\hline $\begin{array}{c}\text { Procedimentos de } \\
\text { atenuação }\end{array}$ & $\begin{array}{c}\text { Tipos de recursos } \\
\text { atenuadores }\end{array}$ & \multicolumn{1}{|c}{ Definições } & Ocorrências/exemplos \\
\hline \hline & $\begin{array}{c}\text { Voz passiva, de } \\
\text { impessoalidade e } \\
\text { de indeterminação } \\
\text { do sujeito }\end{array}$ & $\begin{array}{l}\text { Deslocam } \\
\text { responsabilidades: o } \\
\text { autor passa a ser } \\
\text { instrumento de } \\
\text { outras pessoas ou } \\
\text { instituições, } \\
\text { distanciando-se do } \\
\text { evento comunicativo }\end{array}$ & $\begin{array}{l}\text { - Nesse sentido, observa- } \\
\text { se que...; } \\
\text { - O regulamento prevê a } \\
\text { desocupação... } \\
\text { - Este trabalho objetiva...; } \\
\text { - Foi feita análise } \\
\text { minuciosa...; }\end{array}$ \\
- A conclusão a que se \\
pode chegar...
\end{tabular}

Fonte: adaptado de Lunardelli (2007, p. 29).

\section{Considerações finais}

No contexto da Ciência da Informação, a representação de objetos informacionais desempenha importante papel na organização e circulação da informação, do conhecimento registrado. O resumo é caracterizado como texto ou microtexto de caráter argumentativo, pois expõe e defende resultados de estudos realizados e sua elaboração segue padrões validados por normas específicas e, consequentemente, por expressivo número de pesquisadores da comunidade científica.

Dentre vários aspectos abordados pelas normas, evidenciou-se a busca pela neutralidade e distanciamento no contexto dessas condensações informacionais. Segundo essa linha de raciocínio, por intermédio do emprego do modo impessoal, da terceira pessoa do singular, da partícula "se", do verbo na voz passiva e outros recursos, seria possível, então, obter a tão desejada objetividade e imparcialidade.

Algumas questões, entretanto, colocam em xeque essa possibilidade. Ao considerar a argumentatividade presente no texto, ou seja, o desejo de persuadir, de convencer a respeito da validade dos resultados obtidos, como pretender que tanto o estudo quanto seu autor possam ser considerados neutros, imparciais? Como concordar com a 
ideia de transferir, de um ser racional para os dados e informações, a responsabilidade pelos resultados obtidos? O pesquisador, então, não é o responsável por sua obra? A concepção de sujeito ativo, pleno de intencionalidade, perpassado por questões ideológicas seria, então, uma falácia?

$\mathrm{Na}$ tentativa de buscar esclarecimentos acerca dessas aparentes contradições, recorreu-se aos aportes teóricos e metodológicos da Linguística Textual, da Análise da Conversação, da Preservação da Face. Em decorrência, é possível afirmar que o desejo de preservar a autoimagem, a face, de minimizar possíveis críticas é recorrente na elaboração dos resumos, pois seus autores lançam mão de recursos linguísticos que propiciam a atenuação da força ilocutória de suas asserções. A opção por determinada palavra em detrimento de outra mais impositiva, uma estrutura frasal menos direta, entre outros mecanismos linguísticos, são estratégias extremamente positivas já que promovem o abrandamento discursivo $e$, com isso, mantêm o equilíbrio na relação colaborativa que se dá, na comunicação científica, entre autor e leitor. O abrandamento ou atenuação, vale lembrar, não deixam de ser marcas do envolvimento que se estabelece entre eles.

Entretanto, o real distanciamento do autor em relação à sua obra, o apagamento da autoria no evento comunicativo, ainda que seja valorizado por algumas linhas de pensamento, não é factível. A impessoalidade não promove o distanciamento do locutor com seu enunciado, uma vez que há intencionalidade, mesmo subjacente, na produção textual. As marcas da subjetividade são desconsideradas por expressivo número de pesquisadores, estudiosos, mas incrustam-se em cada trecho elaborado. De acordo com essa linha de raciocínio, não se pode pensar em distanciamento ou menor envolvimento. O que efetivamente se consegue por meio dessas estratégias linguísticas são efeitos de sentido que sugerem o afastamento ou o não comprometimento do autor com as ideias apresentadas ou o emprego deliberado de recursos linguísticos que simulam o afastamento.

À título de encerramento, ainda que não se tenha esgotado o assunto, vale recorrer a Crestani (2009, p. 89) e ressaltar que

Importa, pois, compreender que objetividade, verdade, oralidade, escrituralidade são efeitos de sentido produzidos pelas escolhas conscientes ou inconscientes - do produtor de texto que se manifestam na superfície textual com o objetivo último de persuasão.

\section{Referências}

ANDRADE, M. L. da C. V. de O. Digressão: uma estratégia na condução do jogo textual-interativo. 1995. 303f. Tese (Doutorado em Semiótica e Linguística Geral) - Faculdade de Filosofia, Letras e Ciências Humanas da Universidade de São Paulo, São Paulo, 1995. 
ASSOCIAÇÃO BRASILEIRA DE NORMAS TÉCNICAS (ABNT). NBR 6028: informação e documentação - resumo - apresentação. Rio de Janeiro, 2003.

BARROS, D. L. P. de. A sedução nos diálogos. In: PRETI, D. (Org.). Diálogos na fala e na escrita. São Paulo: Humanitas, 2005. p. 225-254. (Projetos Paralelos, 7).

BRIZ, A. A atenuação e os atenuadores: estratégias e táticas. Trad. Luiz Antônio da Silva, Adriana Marcelle de Andrade, Ramiro Carlos Humberto Caggiano Blanco. Linha d' Água, n. 6, v. 2, p. 281-314, 2013.

BROWN, P.; LEVINSON, S. C. Politeness: some universals in language use. 2. ed. Cambridge: Cambridge University Press, 1987.

CORACINI, M. J. F. Um fazer persuasivo: o discurso subjetivo da ciência. São Paulo: Educ; Campinas: Pontes, 1991.

COSTA VAL, M. da G. Redação e textualidade. 2. ed. São Paulo: Martins Fontes, 1999.

CRESTANI, L. M. Enunciação e persuasão em textos de diferentes gêneros. Signo, Santa Cruz do Sul, v. 34, n. 57, p. 89-106, jul./dez. 2009. Disponível em: <http://online.unisc.br/seer/index.php/signo/index>. Acesso em: 10 maio 2015.

GALEMBECK, P. de T. Preservação da face e manifestação de opiniões: um caso de jogo duplo. In: PRETI, D. (Org.). O discurso oral culto. 2. ed. São Paulo: Humanitas Publicações FFLCH/USP, 1999. p.173-194. (Projetos Paralelos, 2).

GOFFMAN, E. A elaboração da face: uma análise dos elementos rituais na interação social. In: FIGUEIRA, S. A. (Org.). Psicanálise e Ciências Sociais. Rio de Janeiro: Francisco Alves, 1980. p. 76-114. (Série Psicologia e Psicanálise).

GUIMARÃES, J. A. C. O resumo como instrumento para a divulgação e a pesquisa científica. Revista Brasileira de Educação Especial, Marília, v. 11, n. 1, p. 3-16, jan./abr., 2005.

KOBASHI, N. Y. Resumos documentários: uma proposta metodológica. Revista de Biblioteconomia de Brasília, Brasília, v. 21, n. 2, p. 201-210, jul./dez.1997.

KOCH, I. G. V. A inter-ação pela linguagem. São Paulo: Contexto, 1992. (Coleção Repensando a Língua Portuguesa).

LANCASTER, F. W. Indexação e resumos: teoria e prática. 2. ed. rev. atual. Brasília: Briquet de Lemos, 2004.

LUNARDELLI, R. S. A. Preservação da face: estratégias discursivas na fala dos alunos de Biblioteconomia da UEL. 2007. 111f. Tese (Doutorado em Estudos da Linguagem) - Universidade Estadual de Londrina, Londrina, 2007. 
LUZ, A.C. de O. Critérios para elaboração de resumos. Revista de Biblioteconomia de Brasília, Brasília, v. 20, n. 1, p. 27-40, 1996. Disponível em: <www.brapci.ufpr.br/download.php?dd0=14386>. Acesso em: 2 abr. 2015.

MARCUSCHI, L. A. Análise da conversação. 4. ed. São Paulo: Ática, 1998. (Série Princípios, 82).

MOREIRO GONZÁLEZ, J. A. El contenido de los documentos textuales: su análisis y representación mediante el lenguaje natural. Gijon: Espanha: Trea, 2004.

MÜLLER, M. S.; CORNELSEN, J. M. Normas e padrões para teses, dissertações e monografias. 5. ed. Londrina: Eduel, 2003.

RODRIGUES, C. C. A questão da neutralidade na produção textual. Letras 8, Santa Maria, p. 17-23, jan./jun. 1994.

ROSA, M. de M. Marcadores de atenuação. São Paulo: Contexto, 1992. (Repensando a Língua Portuguesa).

SEVERINO, A. J. Metodologia do trabalho científico. 23. ed. rev. e atual. São Paulo: Cortez, 2002.

TASCHETTO, T. R. A (im)pessoalidade no discurso acadêmico: o desvio marcado pelo sintoma. Fragmentum, Santa Maria, Laboratório Corpus: UFSM, n. 30, p. 27-37, jul./set. 2011. 